\title{
A IMPORTÂNCIA DOS INDICADORES ECONÔMICOS, FINANCEIROS E DE ENDIVIDAMENTO COMO GESTÃO DO CONHECIMENTO NA TOMADA DE DECISÃO
}

\section{EM TEMPOS DE CRISE}

The importance of economic, financial and debt indicators as knowledge management in

decision-making in crisis times

\author{
Rodrigo Regert ${ }^{1}$ \\ Gilberto Medeiros Borges Junior ${ }^{2}$ \\ Sandra Mara Bragagnolo ${ }^{3}$ \\ Joel Haroldo Baade ${ }^{4}$ \\ Recebido em: 24 jun. 2018 \\ Aceito em: 28 ago. 2018
}

Resumo: Nos tempos hodiernos, a crise é uma constante que deve ser levada em consideração para a tomada de decisão. As empresas brasileiras, por estarem inseridas num cenário cuja economia é instável, precisam buscar diariamente informações na contabilidade sobre sua situação financeira, visando extrair dados que auxiliem na tomada de decisão. Tendo em vista isso, o presente artigo tem como objetivo realizar uma abordagem sobre a importância dos principais indicadores econômicos, financeiros e de endividamento como gestão do conhecimento na tomada de decisão. Diante deste contexto, serão abordados conceitos, objetivos, tipos e vantagens da análise econômica, financeira e de endividamento que podem ser realizadas em uma empresa. Para isso, a pesquisa será de forma descritiva com base bibliográfica. Conclui-se que esse estudo dará condições de conhecer a situação econômicofinanceira de uma organização, analisando-a através de três pontos fundamentais: Liquidez, Rentabilidade e Endividamento. Ter ciência disso é essencial para a tomada de decisão, uma vez que a empresa precisa ter conhecimento da sua situação patrimonial para efetuar investimentos e projeções futuras.

Palavras-Chave: Indicadores econômico-financeiros. Gestão do conhecimento. Tomada de decisão.

Abstract: In modern times, the crisis is a constant that must be taken into account for decision making. Brazilian companies, because they are inserted in a scenario in which economy is unstable, need to daily seek information in the accounting about their financial situation, in order to extract data that aid in decision making. Thus, the present

\footnotetext{
${ }^{1}$ Mestre. Universidade Alto Vale do Rio do Peixe - UNIARP. E-mail: regert.rodrigo@gmail.com.

${ }^{2}$ Mestrando. Universidade Alto Vale do Rio do Peixe - UNIARP. E-mail: gilberto93.junior21@gmail.com.

${ }^{3}$ Mestra. Universidade Alto Vale do Rio do Peixe - UNIARP. E-mail: sandra.mara612@gmail.com.

${ }^{4}$ Doutor. Universidade Alto Vale do Rio do Peixe - UNIARP. E-mail: baadejoel@gmail.com.
} 
article aims to make an approach on the importance of the main economic, financial and debt indicators as knowledge management in decision making. Given this context, concepts, objectives, types and advantages of economic, financial and indebtedness analysis that can be carried out in a company will be addressed. For this, the research will be descriptive on a bibliographic basis. It is concluded that this study will provide conditions to know the economic-financial situation of an organization, analyzing it through three fundamental points: Liquidity, Profitability and Indebtedness. Knowing this is essential for decision making, since the company needs to be aware of its financial position to make future investments and projections.

Keywords: Economic indicators. Economic and financial indicators. Knowledge management. Decision-making.

\section{INTRODUÇÃO}

A Contabilidade é uma ciência que tem por objeto o patrimônio das aziendas, o qual é composto pelo conjunto de Bens, Direitos e Obrigações, seu objetivo é o estudo das variações patrimoniais, sejam elas quantitativas ou qualitativas. Sendo assim, a contabilidade vem ganhando espaço nos tempos hodiernos, pois, além de fornecer informações estruturadas, avalia a situação econômica e financeira, possibilitando inferências sobre tendências futuras.

Nesse sentido, os indicadores econômico-financeiros podem propiciar resultados satisfatórios a empresas. Esses indicadores são fundamentais no processo decisório e de gerenciamento, independentemente do porte econômica da empresa.

A gestão do conhecimento tem a finalidade de compartilhar informações entre indivíduos de uma organização. Os indicadores financeiros geram um grande volume de informações sobre a organização e são importantes métodos de avaliação de performance.

A instabilidade do mercado e o aumento da competividade fazem com as empresas necessitem de atualização e monitoramento constante do conhecimento, de forma a potencializar sua capacidade de análise periódica de seus indicadores econômicos e financeiros. Esse conhecimento e capacidade permitem acompanhar seu desempenho no cenário econômico em que a organização se insere. Essa postura tende a levar à otimização de lucros e a redução dos impactos negativos sobre os seus investimentos.

Quando os indicadores não são analisados, as decisões tomadas pelos gestores podem acarretar perdas, dependendo do momento, essas perdas podem ser irreversíveis. Portanto, ter conhecimento e informação atualizados torna-se base para tomada de decisão consistente e assertiva no contexto atual. Nesse cenário, a contabilidade aparece como a responsável pela elaboração e interpretação das informações econômicas e financeiras.

Assim, o presente estudo tem como objetivo realizar uma abordagem sobre a importância dos principais indicadores econômicos, financeiros e de endividamento como gestão do conhecimento para a tomada de decisão. Para isso a pesquisa se desenvolveu de 
forma descritiva com base bibliográfica, onde as informações foram extraídas em artigos científicos, teses de doutorado e livros, impressos ou em sites eletrônicos.

\section{FUNDAMENTAÇÃO TEÓRICA}

Para poder estabelecer relações mais consistentes nas análises, inicia-se a abordagem pela conceituação de gestão do conhecimento para, em seguida, seguir para a compreensão do que é análise econômica, financeira e de endividamento e suas derivações, bem como os tipos de análises e suas emanações.

\section{GESTÃO DO CONHECIMENTO}

As organizações, inseridas em um mercado competitivo, buscam, não somente desenvolver conhecimentos, mas também e principalmente, adequar métodos para que haja gestão desse conhecimento no sentido de tornar tal conhecimento explícito, ou seja, que este torna-se parte do capital da organização. Uma efetiva gestão do conhecimento leva à obtenção de informações em tempo hábil para auxiliar na tomada de decisão. Logo, as organizações mais bem-sucedidas são as que valorizam, investem e transformam o conhecimento em lucratividade.

O século XXI faz parte da tida por muitos como "a sociedade do conhecimento", temse acesso à informação como nunca se teve antes e também facilidades de recursos não disponíveis outrora (como mão de obra barata, recursos de capital mais acessível, facilidades de comunicação e logística) (TERRA, 2000).

Para o bom desenvolvimento e aprendizagem em grupo, é necessário que se transforme o conhecimento tácito, que nada mais é do que o conhecimento que uma pessoa adquiriu ao longo da vida, através de suas experiências, em conhecimento explícito, que é o conhecimento compartilhado, ou seja, é transmitido de maneira clara e objetiva, sem complicações, para os demais (NONAKA; TAKEUCHI, 1997).

De acordo com Hernandes, Cruz e Falcão (2000, p. 3) a "gestão do conhecimento é o processo pelo qual uma organização, consciente e sistematicamente, coleta, cria, organiza, compartilha e quantifica seu acervo de conhecimento para atingir seus objetivos estratégicos".

Para Stewart (1998, apud LUCAS; LUCAS, 2010):

As empresas têm o conhecimento como a matéria-prima mais importante para a realização de seus trabalhos. Dessa forma, o conhecimento tornou-se o elemento primordial e um recurso presente em todas as atividades, visando o sucesso da organização.

Analisar os tópicos relacionados a indicadores econômicos, financeiros e de endividamento geram o conhecimento e informação da situação da organização e quais 
decisões devem ser tomadas para garantir o sucesso empresarial.

\section{ANÁLISE ECONÔMICA E FINANCEIRA}

A análise econômico-financeira advém de uma análise e interpretação das demonstrações contábeis. Através destas análises se evidencia a "saúde" financeira de uma empresa, os resultados obtidos, visam demonstrar a melhor performance para se administrar os recursos e buscar resultados favoráveis e preservar o princípio contábil que é a continuidade da empresa.

De acordo com Soares (2006, p. 45):

A análise econômico-financeira aponta limitações e problema, mas quando manuseada convenientemente, pode tornar-se uma solução preventiva para os seus usuários. As limitações das investigações e aplicações da análise de balanços são de natureza essencialmente financeira. Deste modo, tratando, trabalhando e analisando os dados das demonstrações contábeis, pode-se acrescentar e ampliar a percepção de eventuais imperfeições das demonstrações contábeis.

Marion (2012) afirma que só há condições de conhecer a situação econômicofinanceira de uma empresa por meio de três análises, sendo elas a análise de Liquidez, Rentabilidade e de Endividamento. Para ludícibus (1993, p. 59):

É muito mais útil calcular um certo número selecionado de índices e quocientes, de forma consistente, de período para período, e compará-los com padrões preestabelecidos e tentar, a partir daí, tirar uma ideia de quais problemas merecem uma investigação maior, do que apurar dezenas e dezenas de índices, sem correlação entre si, sem comparações e, ainda, pretender das um enfoque e uma significação absolutos a tais índices e quocientes.

A análise econômico-financeira é um instrumento importante no processo de gerenciamento de uma empresa. Constitui-se de um processo de verificação e entendimento das demonstrações contábeis, obtendo-se a situação da empresa, em seus aspectos operacionais, econômicos, patrimoniais e financeiros (PADOVEZE, 2008).

Os resultados obtidos são interpretados com a finalidade de obter conhecimento dos fatos que acarretam a evolução do patrimônio e, ao mesmo tempo, verificar as tendências futuras da empresa.

Não existem critérios ou padrões que determinem se o diagnóstico do analista está correto. Apesar das técnicas e ferramentas existentes, os analistas podem ter conclusões e visões diferentes da mesma empresa (IUDícIBUS, 2008).

Segundo Zdanowicz (2012, p. 3), "na prática, esses conceitos são muito relevantes para se atingirem a eficiência e a eficácia na gestão empresarial. Para tanto, ela precisa estar focada em resultados, e não em expectativas de mercado".

Ainda de acordo com Zdanowicz (2012, p. 3), a análise econômica: 
[...] estuda a capacidade da organização de gerar resultados positivos e a perspectiva para os próximos anos. Outra finalidade dessa análise é pesquisar se isso está ocorrendo de forma gradual, segura e rentável, ou seja, projetar se ela será autossustentável no futuro.

O resultado econômico poderá ser afetado por fatores externos e internos, o surgimento de um novo concorrente, sazonalidade do mercado, as decisões políticoeconômicas de um país, ou uma greve parcial ou total das atividades de uma empresa (ZDANOWICZ, 2012).

A análise financeira é uma das tarefas mais importante para os contadores, pois o levantamento e a interpretação destas informações contribuem para o desenvolvimento das empresas.

As informações extraídas de uma análise financeira demonstram a capacidade de pagamento de uma empresa. Estes dados podem ser utilizados para contribuir com decisões estratégicas, para uma expansão futura das atividades ou para melhorar o desempenho da organização. Segundo Zdanowicz (2012, p. 4),

A análise financeira estuda a capacidade que a empresa tem para pagar suas obrigações com terceiros na data combinada. Essa análise visa avaliar se a organização está gerando um caixa suficiente para honrar com pontualidade os compromissos assumidos com terceiros.

A análise financeira pode ser aplicada em qualquer tipo de organização, seja ela lucrativa ou não, pois sua utilização não visa encontrar valores exatos e perfeitos que retratem uma empresa perfeita, mas, sim, verificar se os resultados obtidos estão dentro da normalidade das empresas do mesmo ramo (MARION, 2006).

Para obter uma análise concreta e confiável, faz-se necessário verificar um conjunto de indicadores, para, com base nesses resultados, interpretá-los de forma correta, pois uma informação equivocada ou mal interpretada pode acarretar perdas irreversíveis. Também é necessário considerar os acontecimentos no ambiente externo, que podem causar grandes impactos em uma organização (IUDÍCIBUS, 2008).

Ainda mencionando Zdanowicz (2012, p. 67),

A análise financeira estuda, de forma criteriosa, os aspectos pertinentes ás disponibilidades de caixa, comparando-as com as principais variáveis endógenas e exógenas que afetaram a organização. A partir das Demonstrações Financeiras, pode ser realizado uma série de análise financeiras pelo enfoque gerencial, visando avaliar analiticamente o comportamento da empresa.

A partir desses conceitos, é possível verificar a importância da análise econômica e financeira de uma empresa, pois expressa a real situação da mesma perante o mercado em que está inserida. 


\section{Objetivos da Análise Econômico-financeira}

A análise econômico-financeira utiliza dados e informações contábeis para diagnosticar a exata situação em que se encontra a empresa. Já em um segundo momento, projeta o futuro, através dos elementos patrimoniais e de resultados extraídos das demonstrações financeiras, tornando possível definir decisões a serem tomadas sobre questões de curto, médio e longo prazo (ZDANOWICZ, 2012).

Zdanowicz (2012, p. 6) cita os principais objetivos que devem ser considerados nas análises econômico-financeiras e patrimoniais na organização:
a) Analisar a capacidade de gerar resultados (lucro) no período;
b) Avaliar as condições de pagar as obrigações assumidas com pontualidade (caixa);
c) Calcular a rentabilidade sobre o capital investido próprio e total;
d) Definir os melhores indicadores para medir o desempenho empresarial;
e) Estudar as peças contábeis para fins de associação, fusão, cisão ou incorporações.

Nesse sentido, observa-se que o objetivo da análise econômico-financeira é avaliar, calcular e definir os indicadores que evidenciaram a situação patrimonial da entidade. Neste mesmo segmento, ainda Zdanowicz (2012, p. 6) afirma que:

\footnotetext{
As análises auxiliam a direção a se auto avaliar, quanto ao passado sobre os acertos da gestão e, quanto ao futuro, o desafio em continuar focada em resultados mediantes o desenvolvimento gradual, competente e seguro de todas as atividades através de pessoas treinadas e tecnologias modernas.
}

Mais uma vez, nota-se que, para a empresa, a análise econômico-financeira aborda acontecimentos passados e evidencia tendências futuras, contribuindo para a maximização dos lucros e a preservação do princípio contábil da continuidade.

\section{Vantagens da análise econômico-financeira}

Os resultados da análise econômico-financeira fornecem ao administrador uma orientação de grande importância para as decisões a serem tomadas. Através dos índices, o administrador tem a possibilidade de verificar a evolução de seus resultados em determinados períodos e também de compará-los com os resultados de empresas do mesmo ramo, a fim de evidenciar se seus resultados estão dentro da normalidade.

De acordo com Zdanowicz (2012, p. 7), as principais vantagens para a empresa realizar as técnicas das análises são:
a) Determinar a lucratividade (margem) obtida e compará-la com o setor;
b) Calcular o giro (rotação) dos produtos e/ou atividades no período;
c) Apurar o retorno sobre o investimento total e próprio;
d) Projetar a participação dos funcionários nos resultados;
e) Conhecer os níveis mínimos e máximo de liquidez através do fluxo de caixa;
f) Fixar um grau de endividamento aceitável;
g) Ter o prévio conhecimento do ponto de equilíbrio das áreas e produtos; 
h) Adequar o capital de giro ao nível de atividade;

i) Calcular quantos dias, em média, são necessários para financiar o ciclo operacional.

Constata-se que a aplicabilidade da análise econômico-financeira em uma organização torna possível identificar se os resultados são os esperados pela gestão. Logo, verifica-se a importância da validação periódica dos tipos de análise que serão apresentadas a seguir.

\title{
TIPOS DE ANÁLISE ECONÔMICO-FINANCEIRA
}

A análise econômico-financeira pode ser efetuada através dos índices de liquidez, endividamento e rentabilidade.

\section{Índices de Liquidez}

Os índices de liquidez são utilizados para avaliar a capacidade de pagamento da empresa, demonstram se a empresa tem capacidade para saldar seus compromissos. Esta capacidade de pagamento pode ser avaliada, considerando longo prazo, curto prazo e prazo imediato. De acordo Zdanowicz (2012, p. 68), "liquidez é a capacidade financeira que a empresa tem para pagar os compromissos assumidos com terceiros em dia".

\begin{abstract}
A análise de liquidez é realizada através de quocientes. Os índices de liquidez, usualmente utilizados são: imediata, seca, corrente e total. Eles relacionam os bens e direitos com as obrigações da empresa, por intermédio de uma operação de divisão. Afirma-se que os índices de liquidez medem o quanto a organização tem para cada unidade monetária que ela deve a terceiros (ZDANOWICZ, 2012, p. 70).
\end{abstract}

As informações para realizar os cálculos e as análises são extraídos do balanço patrimonial. Os indicadores de liquidez têm por objetivo avaliar a capacidade de pagamento da empresa no período em análise (ZDANOWICZ, 2012).

A elaboração destes indicadores atenderá os usuários internos e externos, denominados stakeholders, em especial aos credores, para avaliação de riscos no momento da concessão de empréstimos. Sendo assim, estes indicadores tornam-se relevantes para a avaliação e projeção da capacidade financeira da empresa no curto e longo prazo.

Liquidez Imediata

O índice de liquidez imediata é utilizado para evidenciar os recursos que estão disponíveis para saldar os compromissos de curto prazo da empresa, utilizando de suas disponibilidades. De acordo com Zdanowicz (2012, p. 70),

Esse indicador informa o quanto de dívidas em curto prazo da empresa pode ser saldado de imediato, ou seja, utilizando-se somente as suas disponibilidades (caixa, bancos e aplicações financeiras de pronto resgate) existente no momento. 
O Cálculo da liquidez imediata é realizada através da seguinte fórmula:

Equação 1 - Liquidez Imediata.

$\mathrm{Li}=$<smiles>[2H]P[18F]</smiles>

$\mathrm{Li}=$ Liquidez imediata;

D = Disponibilidades (caixa, bancos e aplicações

no mercado financeiro de resgate imediato);

$\mathrm{PC}=$ Passivo Circulante (todas as obrigações

venciveis até um exercício social).

Fonte: (ZDANOWICZ, 2012).

A liquidez imediata examina a capacidade de pagamento das obrigações da empresa a curto prazo, utilizando de suas disponibilidades. Através desta equação, pode-se dar início à análise dos indicadores da empresa. Vale ressaltar que um índice isolado possui poucas informações para tomada de decisão.

\subsubsection{Liquidez seca}

O índice de liquidez seca tem como objetivo verificar a capacidade de pagamento da empresa no curto prazo, sem levar em consideração os valores de estoques, por serem elementos menos líquidos do ativo circulante.

Nesse sentido, Zdanowicz (2012, p. 72) esclarece que:

A liquidez seca informa a capacidade financeira da empresa em pagar suas obrigações de curto prazo, valendo-se dos seus ativos mais líquidos no período considerando, ou seja, as disponibilidades e os valores a receber líquidos de vendas (os recebíeis).

O índice de liquidez seca é calculado pela seguinte fórmula: 
Equação 2 - Liquidez Seca.

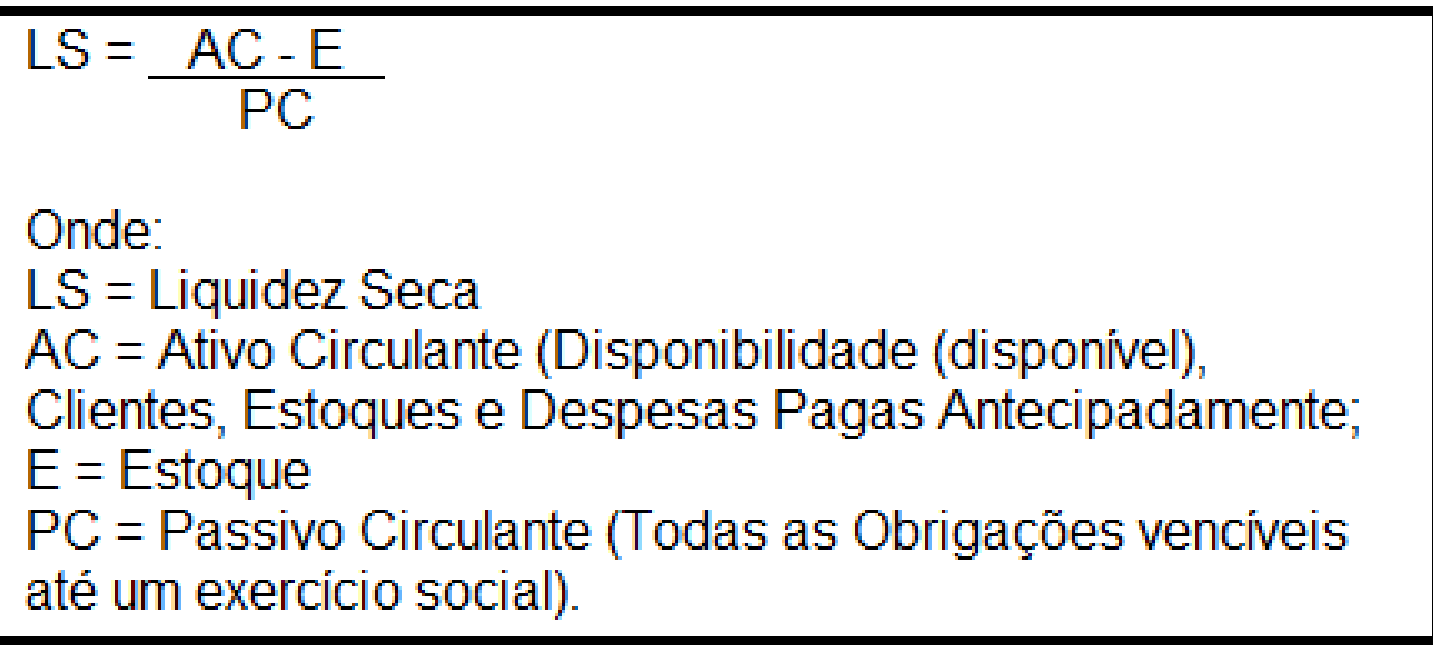

Fonte: (ZDANOWICZ, 2012).

O índice de liquidez seca aponta a capacidade financeira da empresa pagar suas obrigações de curto prazo, utilizando dos seus ativos mais líquidos no período.

Liquidez corrente

O índice de liquidez corrente é utilizado para evidenciar o quando a empresa possui de bens e direitos circulantes de curto prazo (Ativo circulante), para cumprir com suas obrigações de curto prazo (Passivo Circulante).

De acordo com Marozini apud Helfert (2005, p. 62):

O índice mais utilizado para avaliar a exposição à dívida representada no balanço patrimonial é o índice de liquidez corrente. Ela relaciona os ativos circulantes com os passivos circulantes e é uma tentativa de demonstrar a segurança dos direitos dos possuidores da dívida atual no caso de inadimplência.

O índice de liquidez corrente (LC) é calculado pela seguinte fórmula: 
Equação 3 - Liquidez corrente.

\section{$L C=\underline{A C}$ \\ $\mathrm{PC}$ \\ Onde: \\ $\mathrm{LC}=$ Liquidez Corrente \\ $\mathrm{AC}=$ Ativo Circulante \\ $\mathrm{PC}=$ Passivo Circulante}

Fonte: (ZDANOWICZ, 2012).

A liquidez corrente é a confrontação do ativo circulante com o passivo circulante, evidenciando se a organização possui recursos suficientes para fazer frente a suas obrigações de curto prazo. Neste sentido, Silva (2012, p. 271) afirma que "alguns autores mencionam que o índice tem que ser maior que 1 (um), outros consideram que acima de 1,5 (um e meio) já é muito bom".

Liquidez total

A liquidez total considera quanto a empresa possui de bens e direito realizáveis no curto e longo prazo, para fazer frente a suas obrigações de curto e longo prazo. No dizer de Zdanowicz (2012, p. 73):

A liquidez total é também denominada por liquidez geral. A Liquidez total informa a situação financeiras da empresa de longo prazo, ou seja, é a relação entre a totalidade dos capitais circulantes próprios de curto e longo prazo da organização (exceto os itens do Ativo Fixo) em relação ao conjunto dos capitais de terceiros captados pela empresa.

O cálculo da Liquidez total (Lt) é realizado através da seguinte fórmula: 
Equação 4 - Liquidez Total.

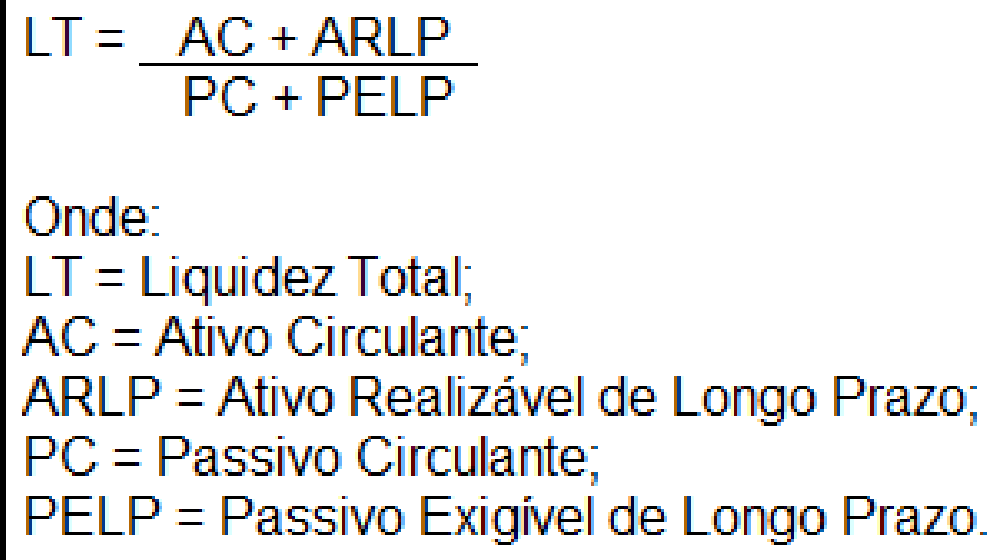

Onde:

$\mathrm{LT}=$ Liquidez Total;

$\mathrm{AC}=$ Ativo Circulante;

ARLP = Ativo Realizável de Longo Prazo;

$P C=$ Passivo Circulante;

PELP = Passivo Exigivel de Longo Prazo.

Fonte: (ZDANOWICZ, 2012).

A liquidez total aponta quanto a empresa tem de recursos financeiros, sem envolver seu ativo permanente para saldar suas obrigações com terceiros de curto e longo prazo. Este índice é o mais interessante para a empresa avaliar sua situação financeira sem envolver os ativos fixos.

\section{Índices de Endividamento}

Os índices de endividamento apontam se a empresa é financiada por capitais de terceiros ou por capitais próprios. Através destes, analisa-se se a dívida da empresa possui seu vencimento no curto ou longo prazo.

Índice de Participação de Capitais de Terceiros (PCT)

O indicador de garantia de capital de terceiros demonstra a proporção do capital de terceiros sobre o capital próprio, informando se a empresa tem dependência ou não de recursos de terceiros para viabilizar suas atividades (ZDANOWICZ, 2012).

Este índice representa o percentual de capital de terceiros sobre o total do passivo. Sendo seu cálculo efetuado através da seguinte fórmula: 
Equação 5 - PCT.

$$
\mathrm{PCT}=\frac{\mathrm{PC}+\mathrm{PENC}}{\mathrm{PC}+\mathrm{PENC}+\mathrm{PL}}
$$

Onde:

PCT = Participação de Capitais de Terceiros;

PC = Passivo Circulante;

PENC = Passivo Exigivel Não Circulante;

$\mathrm{PL}=$ Patrimônio Líquido.

Fonte: (MARION, 2012).

O Passivo compreende a origem dos recursos, representado pelas obrigações com capitais de terceiros e próprio. Desta forma, este índice procura evidenciar qual o valor da Participação de Capitais de Terceiros sobre o valor total do passivo.

Garantia do Capital Próprio ao Capital de Terceiros - (GCPCT)

O índice Garantia do Capital Próprio ao Capital de Terceiros indica o montante do Patrimônio Líquido (PL) em relação ao Passivo Exigível. Sendo, seu cálculo efetuado através da seguinte fórmula:

Equação 6 - GCPCT.

$$
\text { GCPCT }=\frac{P L}{\mathrm{PC}+\mathrm{PENC}}
$$

Onde:

GCPCT = Garantia do Capital Próprio ao Capital de

Terceiros;

$\mathrm{PL}=$ Patrimônio Liquido;

PC = Passivo Circulante;

PENC = Passivo Exigível Não Circulante.

Fonte: (MARION, 2012).

Este indicador vai demonstrar se empresa é dependente ou não de capital de terceiros para executar suas atividades. Para Zdanowicz (2012), se o resultado for inferior que a unidade, 
significa que há uma participação maior de capitais de terceiros, verificando-se, nesta situação, que a empresa está alavancando seu negócio com capitais alheios.

Composição do Endividamento (CE)

O indicador de composição de endividamento demonstra quanto da dívida da empresa deverá ser pago no curto e longo prazo, analisando sobre o total das obrigações da empresa. O cálculo será efetuado através da seguinte equação:

Equação 7 - Composição do Endividamento.

$\mathrm{CE}=\frac{\mathrm{PC} \times 100}{\mathrm{PC}+\mathrm{PELP}}$

Onde:

$\mathrm{CE}=$ Composição do Endividamento;

$\mathrm{PC}=$ Passivo Circulante;

PELP = Passivo Exigível Longo Prazo

Fonte: (SILVA, 2001).

O índice de composição do endividamento mostra as características do endividamento da empresa quanto ao vencimento das suas obrigações. Quanto mais dívidas para pagar em curto prazo, maior será a necessidade de a empresa gerar recursos para honrar seus compromissos.

\section{Índices de Rentabilidade}

Os índices de rentabilidade procuram demonstrar o resultado das operações realizada pela empresa, evidenciando qual foi a rentabilidade sobre os capitais investidos. É um dos principais indicadores de desempenho de um negócio.

Taxa de Retorno Sobre o investimento - TRI

A Taxa de Retorno sobre o Investimento - TRI - mede a eficácia da administração de uma empresa em termos de geração de lucros com os ativos disponíveis (GITMAN, 2004). O cálculo da taxa de retorno sobre o investimento ocorre através da seguinte fórmula: 


$$
\mathrm{TRI}=\frac{\mathrm{LL}}{\mathrm{AT}}
$$

Onde:

TRI = Taxa de Retorno sobre Investimento;

LL = Lucro Liquido;

AT = Ativo Total.

Fonte: (MARION, 2012).

A TRI vai apontar o período que a empresa necessita para obter o retorno de seu investimento. É por meio desta taxa que o investidor pode analisar se é viável investir ou não em uma empresa.

Taxa de Retorno Sobre o Patrimônio Líquido (TRPL)

O índice de rentabilidade do patrimônio líquido tem objetivo de demonstrar para o acionista o retorno obtido sobre o capital investimento. O cálculo do retorno sobre o patrimônio líquido será efetuado através da seguinte fórmula:

Equação 9 - Taxa de Retorno sobre o Patrimônio Líquido.

$$
\begin{aligned}
& \text { TRPL }=\frac{\mathrm{LL}}{\mathrm{PL}} \\
& \text { Onde: } \\
& \text { TRPL = Taxa de Retorno sobre o Patrimônio Liquido; } \\
& \mathrm{LL}=\text { Lucro Liquido; } \\
& \mathrm{PL}=\text { = Patrimônio Liquido. }
\end{aligned}
$$

Fonte: (MARION, 2012).

Este indicar vai medir a performance da empresa, mostrando se ela está ou não gerando rentabilidade aos seus acionistas. Os indicadores de rentabilidade têm a função de proporcionar ao acionista a visão da sua empesa diante do mercado onde a mesma está 
inserida e ainda comparar se o retorno está sendo maior que outros investimentos existentes no mercado financeiro, como por exemplo: poupança, Certificado de Depósito Bancários (CDB), Tesouro Direto, Letra de Crédito Imobiliário (LCA) e Letra de Crédito do Agronegócio (LCA).

Através desta análise, o acionista pode verificar a viabilidade de seu investimento e tomar a decisão se continua ou encerra as suas atividades.

\section{ANÁLISE DOS RESULTADOS}

Os indicadores econômicos, financeiros de endividamento e a gestão de conhecimento são temas que preocupam as empresas diariamente. Isso se deve à alta competitividade e a velocidade com que um mercado evolui. A atualização e o monitoramento constante das informações são cruciais para a tomada de decisão.

Com base nas informações obtidas através da pesquisa descritiva e bibliográfica, podese afirmar que os indicadores econômicos, financeiros de endividamento e a gestão de conhecimento são ferramentas importantes para o processo decisório dentro de uma organização. Isso se deve ao fato de que os números e indicadores são importantes e fundamentais, mas, em contrapartida, precisam de um tratamento eficiente, moldado pelo conhecimento e pela inteligência das organizações, presentes, como é de se esperar, nas pessoas.

Quando não se tem conhecimento dos indicadores econômico-financeiros, as decisões tomadas podem acarretar perdas. Logo, em tempos de complexidade, o conhecimento torna-se primazia para as organizações.

Nos dias de hoje, é de suma importância que se invista no capital humano para que a organização possa se desenvolver e ter o seu lugar no mercado. Dessa forma, a presente discussão contribui para as pessoas que atuam nas áreas administrativas, visando auxiliar e contribuir no desenvolvimento do conhecimento científico.

\section{CONSIDERAÇÕES FINAIS}

Este artigo teve como objetivo contextualizar a importância dos principais indicadores econômicos, financeiros de endividamento e gestão do conhecimento na tomada de decisão no dia a dia de uma empresa.

A informação e o conhecimento são recursos fundamentais no processo decisório de uma organização. A necessidade de informações confiáveis faz com que a contabilidade desenvolva um sistema de informação que permita mensurar a situação econômica da empresa, aplicando métodos e conceitos que produzam informações consistentes para embasar a tomada de decisões dos gestores. 
As informações de uma organização são constantemente comparadas com as de outras organizações, as quais atuam no mesmo segmento. Essas mesmas informações também possibilitam ao administrador estabelecer comparação em um contexto geral do desempenho da empresa diante do cenário econômico no qual está inserido, com vistas a planejar seu futuro e potencializar suas capacidades competitivas.

Assim, as organizações podem contar com a gestão do conhecimento por meio da contabilidade, gerando indicadores e informações úteis, consideradas como primazia no mundo dos negócios, visando a sobrevivência e a competividade das empresas.

Com isso, pode-se concluir que o trabalho dos profissionais da área contábil compõe o capital intelectual de uma organização, configurando-se como conhecimento fundamental na geração de indicadores. Isso permite verificar a extrema importância do conhecimento para uma gestão estratégica competitiva.

Neste contexto, a contabilidade tem se mostrado como ferramenta empresarial importante, demonstrando o quanto é relevante para a empresa ter conhecimento e domínio das informações econômicas e financeiras, não apenas como índices isolados, mas como uma gama de indicadores que permitem um diferencial em termos de conhecimento sobre sua situação econômico-financeira e, consequentemente, de sua vantagem competitiva.

\section{REFERÊNCIAS}

HERNANDES, Carlos Alberto.; CRUZ, Cláudio Silva da.; FALCÃO, Sérgio Dagnino. Combinando o Balanced Scorecard com a Gestão do Conhecimento. Caderno de Pesquisas em Administração. São Paulo, vol. 01, n. 12. 2000. Disponível em:

<http://sistemas.aids.gov.br/incentivo/Biblioteca/Gestao_governanca/bsc_e_gestao_do_con hecimento.pdf>. Acesso em: 21 nov 2017.

IUDÍCIBUS, Sérgio de. Teoria da Contabilidade. São Paulo: Atlas, 1993.

IUDÍCIBUS, Sérgio de. Análise de Balanços. 9. ed. São Paulo: Atlas, 2008.

LUCAS, Douglas Ribeiro; LUCAS, Denilson da Silva. Capital Intelectual: Conhecimento, Habilidade e Competências que Geram Receitas. Revista Mineira de Contabilidade. Minas Gerais, 2010, vol. 2, n. 38. Disponível em:

<http://revista.crcmg.org.br/index.php?journal=rmc\&page=article\&op=view\&path\%5B\%5D=3 52\&path\%5B\%5D=156>. Acesso em: 21 nov 2017.

MARION, José Carlos. Análise das Demonstrações Contábeis: Contabilidade Empresarial. 7. ed. São Paulo: Atlas, 2012.

MOROZINI, João Francisco. Análise Econômico-Financeira de Sociedade Anônimas em Precesso de Concordata na Cidade de Curitiba-PR. 2005. 171 f. Dissertação (Mestrado em Ciências Contábeis - área de Controladaria) - Curso de Mestrado em Ciências Contábeis. FURB, 
Universidade Regional de Blumenau, Blumenau. Disponível em:

<http://bdtd.ibict.br/vufind/Record/FURB_d754307c1abcd8b1db75ccfde7b70636>. Acesso em: 21 nov 2017.

NONAKA, Ikujiro; TAKEUCHI, Hirotaka. Criação de conhecimento na empresa. Rio de Janeiro: Elsevier, 1997.

PADOVEZE, C. L. Contabilidade Gerencial: um enfoque em sistema de informação contábil. 5. ed. São Paulo: Atlas, 2008.

SILVA, José Pereira da. Análise Financeiras das Empresas. 5. ed. São Paulo: Atlas, 2001.

SOARES, Maria Aparecida. Análise de Indicadores para Avaliação de Desempenho EconômicoFinanceiro de Operadoras de Planos de Saúde Brasileiras: Uma Aplicação da Análise Fatorial. 2006. 122f. Dissertação (Mestrado em Ciência Contábeis) Curso de Mestrado em Ciências Contábeis. USP, Universidade de São Paulo, São Paulo. Disponível em: <http://www.teses.usp.br/teses/disponiveis/12/12136/tde-15122006-121519/pt-br.php>. Acesso em: 21 nov 2017.

TERRA, José Claudio Cyrineu. Gestão do conhecimento: o grande desafio empresarial. São Paulo: Negócios, 2000.

ZDANOWICZ, José Eduardo. Finanças Aplicadas para Empresas de Sucesso. São Paulo: Atlas, 2012. 